\title{
GARCILASO Y LA AMISTAD
}

Antonio Alatorre*

En la Égloga I ("El dulce lamentar de dos pastores...") Garcilaso dramatiza y estiliza maravillosamente los dos grandes dolores de su vida: primero, el rechazo de su adorada Isabel Freire, a quien conoció en 1526 (cuando él tenía 25 años) y que en 1528 se casó con un tal Antonio de Fonseca; y segundo, la muerte de Isabel en 1533 o 1534. El Garcilaso del primer dolor se llama Salicio (" $\mathrm{OOh}$ más dura que mármol a mis quejas...!/ ...mi amada hiedra, / de mí arrancada, en otro muro asida, / y mi parra en otro olmo entretejida... / Salid sin duelo, lágrimas, corriendo"), y el del segundo dolor se llama Nemoroso ("Corrientes aguas, puras, cristalinas... / ¿Quién me dijera, Elisa, vida mía..., / que había de ver con largo apartamiento / venir el triste y solitario día / que diese amargo fin a mis amores?").

El primer dolor se expresa en otros lugares, por ejemplo en los sonetos "Cuando me paro a contemplar mi estado...", "Pensando que el camino iba derecho...", "Por ásperos caminos he llegado...", "Mi lengua va por do el dolor la guía...", "Estoy contino en lágrimas bañado...", "En fin a vuestras manos he venido..." ("para que sólo en mí fuese probado / cuánto corta una espada en un rendido") y, muy largamente, en la Canción IV: "El aspereza de mis males quiero / que se muestre también en mis razones..."

El segundo dolor tiene asimismo varias otras expresiones. La muerte tan repentina de la amada -estando él ausente de España- ha sido

* El Colegio de México. 
ANTONIO ALATORRE

también la muerte definitiva de cualquier esperanza que aún pudiera tener Garcilaso, así fuera sólo la de verla una vez más: "En poco espacio yacen los amores..." (Soneto XXV); "¡Oh, cuánto bien se acaba en solo un día...!" (Soneto XXVI); "Pues en una hora junto me llevastes / todo el bien que por términos me distes" (Soneto X); "pues ha sido en una hora / todo aquello deshecho / en que toda mi vida fue gastada" (Canción III).

El ensimismamiento torturado, la concentración en el dolor, es la nota más característica de su poesía. "Estoy", dice en el Soneto XII, "en tanta confusión, que nunca oso / fïar el mal de mí que lo poseo": no osa hacerse a sí mismo una confidencia tan horrible, no osa confesarse algo que, sin embargo, lo tiene lacerado y destrozado: el rechazo inexorable de Isabel. Por eso también huye de los amigos. El dolor es muy suyo, y se niega a compartirlo con ellos: su compañía le es "amarga y dura" (Soneto XVII). No quiere oír un “¡Habla! ¡Dinos qué te pasa!”

Ese Garcilaso que huye de los amigos se llama Albanio en la Égloga II (escrita en vida de Isabel). Los amigos, vivamente preocupados por su estado, se llaman Salicio y Nemoroso, como los pastores de la Égloga I. Testigo involuntario de una crisis de dolor de Albanio, Salicio

8 le dice: "Albanio, deja el llanto, que en oíllo / me aflijo". "¿Quién presente está a mi duelo?", pregunta Albanio; y Salicio contesta: “Aquí está quien te ayudará a sentillo”. ¡Para eso son los amigos! Pero Albanio no está de humor:

¿Aquí estás tú, Salicio? Gran consuelo me fuera en cualquier mal tu compañía, mas tengo en esto por contrario al cielo.

Ablandado a fuerza de ruegos, Albanio le cuenta a Salicio cómo gozó en un tiempo la apacible amistad de Camila (así se llama Isabel en esta Égloga), hasta que en un aciago día todo acabó "no en pena, no en congoja: en cruda muerte". Pero se niega a entrar en explicaciones ("Decir ya más no es bien que se consienta") y se encierra en su mutismo tenebroso. Salicio vuelve a la carga: 


\begin{abstract}
Albanio, si tu mal comunicaras con otro que pensaras que tu pena juzgaba como ajena, o que este fuego nunca probó, ni el juego peligroso de que tú estás quejoso, yo confieso que fuera bueno aqueso que ahora haces,
\end{abstract}

pero él no es un extraño, sino un amigo que sabrá comprenderlo:
Al menos aprovecha, yo te digo, para que de un amigo que adolezca otro se compadezca, que ha llegado de bien acuchillado a ser maestro.

Salicio, pues, pone su larga experiencia al servicio del joven Albanio, y lo acosa con preguntas y consejos. Pero Albanio no da su brazo a torcer: "¿Cuán fácilmente / ...el sano da consejos al doliente!" "“respuesta tan aceda y odiosa", comenta Salicio). Al fin accede a seguir con su historia, pero a condición de que, al terminar, se vaya Salicio y lo deje llorar a solas.

Salicio se va, en efecto, y entonces viene el dramático encuentro de Albanio con la hermosa y desamorada Camila. Después de soportar una andanada de reproches y recriminaciones, ella mañosamente se escapa, dejando sumido al amante "no en pena, no en congoja", sino en verdadera locura: se pone a desvariar, mientras Nemoroso y Salicio lo escuchan e intercambian comentarios. Pero cuando Albanio va a echarse de cabeza en una fuente, comprenden que ha llegado el momento de actuar: "Salgamos, que ya empieza un furor nuevo" (una locura más seria), dice Salicio.

Este pasaje de la intervención de los amigos es el más animado, el más teatral de la Égloga II. Y lo mejor es la inesperada irrupción de lo cómico en medio del drama. Furioso al ver que Salicio le estorba su propósito de suicidio, Albanio, con la fuerza que suelen tener los locos violentos, lo agarra de la garganta. Salicio pide ayuda, pero Nemoroso, 
ANTONIO ALATORRE

con mucha flema, le dice que él solo, sin ayuda, podrá "desenclavijarse", y que el espectáculo es divertido. A lo cual sigue este diálogo:

-iQué tiempo de placeres y de burlas!

¿Con la vida te burlas, Nemoroso?

¡Ven! ¡Ya no estés donoso!

-Luego vengo.

En cuanto me detengo aquí un poco, veré cómo de un loco te desatas.

Pero muy pronto ve Nemoroso que hay que intervenir: "Ya aquello va de veras. ¡Suelta, loco!': y después de someter al loco entre los dos, lo atan de pies y manos para neutralizarlo. Algo más sereno, Albanio le hace un reproche a Salicio:

¡Negra fue aquella lucha que contigo

hice. ¡Qué tal castigo dan tus manos!

¿No éramos como hermanos de primero?

En vez de justificarse diciendo que a veces los amigos tienen que usar de violencia con el amigo, Salicio responde simplemente:
Albanio, compañero, calla agora
y duerme aquí algún hora y no te muevas.

Esto es, en efecto, lo que sucede. Y mientras duerme Albanio, sus amigos discurren qué hacer para que sane de su locura. Nemoroso se acuerda de un anciano llamado Severo, ${ }^{1}$ que tiene fama no ya de sabio, sino de mago. ¿Qué mejor psiquiatra para el pobre esquizofrénico? No se nos cuenta la entrevista del loco con el médico, pero el diálogo final de Salicio y Nemoroso los muestra seguros de que Severo le hará recobrar la razón perdida:

${ }^{1}$ Era un personaje real: fray Severo, humanista italiano, preceptor de latinidad de los hijos del Duque de Alba. 
-Recoge tus ovejas y las mías...

Yo solo me averné con nuestro loco, que, pues él hasta aquí no se ha movido, la braveza y furor debe ser poco...

Adiós, hermano.

-Adiós, Salicio amigo.

La numeración de las dos primeras églogas de Garcilaso no corresponde a la cronología. La Égloga II, escrita en vida de Isabel, es anterior a la Égloga I, en la cual se llora su muerte. Entre una y otra no median quizá sino unos meses. Así, pues, Salicio y Nemoroso estaban frescos, recién creados, y Garcilaso decidió ponerlos de nuevo en escena, pero alterando radicalmente sus funciones: primero (Égloga II) representaban a los amigos que se preocupaban por su contratiempo amoroso, y ahora (Égloga I) los convierte Garcilaso en representaciones de sí mismo, en imágenes de sus dos dolores.

Es evidente que, al autorretratarse en Albanio, recargó mucho los colores de la desesperación y la locura. Entre 1526 (cuando conoció a Ișabel) y 1533 (cuando escribió esa Égloga en que se nos muestra tan enloquecido) había llevado una vida activísima como diplomático -hombre de confianza de Carlos V y del Duque de Alba- y también como militar. Era hombre extrovertido, sociable, de buen humor. ${ }^{2} \mathrm{Si}$ exageró las tintas sombrías en su Albanio fue seguramente para mejor arrojarlo de sí, para deshacerse de él. Por eso es tan significativa la escena en que Nemoroso deja durante un rato que Salicio se la arregle solo. Albanio estará bien loco, pero el Garcilaso que imagina y construye la escena está en sus cinco sentidos y no ha perdido el humor.

Además, en un jubiloso soneto, “¡Gracias al cielo doy, que ya del cuello / del todo el grave yugo he sacudido...!", Garcilaso ha cantado su liberación: ¡no más penas amorosas, no más esclavitud! ¡Pobre de

${ }^{2}$ Ejemplo de esto son sus coplas a Boscán "porque estando en Alemaña danzó en unas bodas", y a cierto Luis de la Cueva "porque bailó en Palacio con una dama que llamaban La Pájara". 


\section{ANTONIO ALATORRE}

quien, "embebecido / en error; en engaño adormecido, / sordo a las voces que le avisan dello", se mete en tan furiosas tormentas! (infeliz Albanio, sordo a las voces de sus amigos!). Más aún: en 1532 se ha enamorado en Nápoles de una dama cuyo nombre se desconoce, y su amor ha sido correspondido. ${ }^{3}$ De esta venturosa aventura napolitana habla Garcilaso en el Soneto XXVIII ("Boscán, vengado estáis, con mengua mía..."). En un momento de desesperación le habrá dicho a su amigo: "Reniego del Amor, y juro que nunca más me dejaré atrapar en sus redes odiosas", y ahora le dice: "Perdón, se me fue la lengua; he reincidido, y me siento el más feliz de los mortales":

...Sabed que en mi perfecta edad, y armado, con mis ojos abiertos, me he rendido al Niño que sabéis, ciego y desnudo.

De tan hermoso fuego, consumido nunca fue corazón. Si preguntado soy lo demás, en lo demás soy mudo.

En una carta al mismo Boscán, impresa como "Elegía II", vuelve a 12 hablar de esos amores napolitanos. La escribió hacia octubre de 1535, en Sicilia, donde las tropas imperiales descansaban de la campaña de Túnez y se disponían a entrar triunfalmente en Nápoles. En cuanto menciona a Nápoles - con perífrasis: la patria de la sirena Parténope-, piensa Garcilaso en el "nido" que allí dejó unos meses antes, y fluye el caudal de las confidencias:

Allí mi corazón tuvo su nido un tiempo ya, más no sé, triste, agora o si estará ocupado o desparcido.

De aquesto un frío temor así a deshora por mis huesos discurre, en tal manera que no puedo vivir con él una hora...

${ }^{3}$ Hay que hacer notar, por cierto, que Garcilaso tenía mujer e hijos en Toledo; se había casado antes de conocer a Isabel Freire. 
Garcilaso, que recuerda (entre líneas) sus amores con Isabel Freire, tiene la consciencia de haber sido predestinado al dolor. Sin duda en Nápoles va a repetirse la historia. Pero él -tal es su ceguera-prefiere abrazarse a un "dulce engaño", dejándose morir "como aquel que en un templado / baño metido, sin sentillo muere, / las venas dulcemente desatado".

Y al punto piensa en la suerte, tan distinta, de su amigo Boscán, que vive en Barcelona tranquilo y feliz con su mujer legítima, Ana Girón:

Tú que en la patria, entre quien bien te quiere, la deleitosa playa estás mirando y oyendo el son del mar que en ella hiere...,

alégrate, que más hermosa llama que aquella que el troyano encendimiento pudo causar, el corazón te inflama.

No tienes que temer el movimiento de la fortuna con soplar contrario, que el puro resplandor serena el viento. ${ }^{4}$

No se sabe si en noviembre de ese año de 1535 , cuando los imperiales entraron en Nápoles, tuvo Garcilaso la alegría de hallar intacto el nido, no "ocupado" ni "desparcido", y continuó dichosamente su relación con la anónima dama. Yo estoy convencido de que así fue. Es un hecho que, a diferencia de los amores tempestuosos, los amores felices "no hacen historia". ${ }^{\mathrm{Y}}$ además, en una de sus últimas poesías, la Canción $V$, escrita ya en Nápoles, se nos muestra Garcilaso tan distinto de

${ }^{4} \mathrm{El}$ amor de Boscán por su mujer es una "llama". más hermosa que la que causó el incendio de Troya (o sëa la pasión adúltera de Paris y Helena). El amor conyugal tiene la virtud de conjurar las tormentas (fortuna es 'tempestad en el mar').

${ }^{5}$ En todo caso, el intermedio de bonanza y gozo duraría poco. La entrada en Nápoles fue el 25 de noviembre de 1535, y en marzo o abril de 1536, por órdenes de Carlos V, salió Garcilaso de Nápoles para nunca más volver. Murió trágicamente en octubre de ese año, en Niza. 


\section{ANTONIO ALATORRE}

como lo hemos conocido, que parece otro. Lejos de ser el loco rematado de quien tienen que ocuparse los amigos, es él ahora el amigo que tiene que hacer algo, y urgentemente, por el infeliz Mario Galeota, ${ }^{6}$ enloquecido por los desdenes de la hermosa Violante Sanseverino (la "flor" del barrio napolitano de Gnido). No piensa, como el Nemoroso de la Égloga II, en un Severo que a fuerza de sabios consejos haga recuperar a Mario la razón, sino que discurre un medio más radical: dirigirse a la propia Violante para decirle con mucha suavidad: "Tú, hermosa niña, serías la perfección misma de no ser por tu desdén para con cierto muchacho a quien estás matando":

Hablo de aquel cativo

de quien tener se debe más cuidado,

que está muriendo vivo,

al remo condenado,

en la concha de Venus amarrado...

Sí, Mario Galeota está hecho un galeote del Amor. ¡Desdichado! ¿Y por culpa de quién? Por culpa de Violante. "Por ti", comienzan las

14 cuatro estrofas siguientes ("anáfora" se llama esta figura): por ti ya no se interesa Mario en los deportes ecuestres; por ti ha dejado el viril pasatiempo de la esgrima; por ti ha colgado su laúd y se dedica a llorar todo el día; y sobre todo,

por $t i$ el mayor amigo

le es importuno, grave y enojoso:

yo puedo ser testigo,

${ }^{6}$ Poco antes, desde Túnez, donde en un encuentro con los moros había recibido heridas en el brazo derecho y en la lengua, Garcilaso le había mandado a Mario Galeota el juguetón Soneto XXXV, donde dice que esas heridas se las hizo su verdadero enemigo, el Amor, para castigarlo por haber empleado brazo y lengua en escribir y hablar contra él y su "vil naturaleza". Pero ¡que se cuide el maldito Amor! Él, Garcilaso, sabrá desquitarse. 
que ya del peligroso

naufragio fui su puerto y su reposo, ${ }^{7}$

y ahora en tal manera

vence el dolor a la razón perdida, que ponzoñosa fiera

nunca fue aborrecida

tanto como yo de él, ni tan temida.

En Mario Galeota se repite, punto por punto, la situación de aquel Albanio que, teniendo por importunos y odiosos a sus dos amigos, huía de ellos como si fueran víboras. Ahora Garcilaso puede hablar con las palabras de Salicio: "ha llegado / de bien acuchillado a ser maestro". ¡Es preciso que Mario recobre la razón y vuelva a ser amigo de sus amigos! ¿Y quién, sino la hermosa flor de Gnido, tiene el remedio? Por eso el poema termina con una amonestación a la desdeñosa muchacha: " $i C u i d a d o$ ! No vaya a sucederte lo que a la cruel Anaxárete, que no se dolió de su enamorado Ifis sino cuando éste, en su desesperación, ya se había ahorcado ("¡oh tarde arrepentirse!"), y por dura, por insensible, los justicieros dioses la convirtieron en estatua de piedra. Amonestación tremebunda, pero juguetona.

La Canción V, de tan deleitosa lectura, ${ }^{8}$ no brotó de un espíritu torturado, sino de un hombre sereno, armonioso, sonriente, en paz consigo mismo, que con toda naturalidad y mejor que nadie puede ponerse en

${ }^{7}$ En otras ocasiones Garcilaso fue el confidente de Mario, pero ahora Mario no se deja ayudar: (El ya de "que ya del peligroso..." es un italianismo; significa 'en otro tiempo'.)

${ }^{8} \mathrm{La}$ "forma" (que hace un todo con el "contenido") es delgada, leve, casi etérea: estrofitas de sólo cinco versos, y tres de ellos cortos. (Fue esta Canción la que introdujo la forma lira en la poesía de nuestra lengua.) Es muy revelador el contraste con la Canción IV, tan ensimismada, tan cargada de cavilaciones, y cuya "forma" es el colmo de la densidad: estrofas de veinte versos, $y$ todos largos (salvo uno). Garcilaso se propuso hacerla concordar con el "contenido": "El aspereza de mis males quiero / que se muestre también en mis razones". 
el pellejo de Mario y que, inspirado pura y simplemente por la experiencia, acude con gracia y humor a ayudar al amigo. La límpida fuente de la Canción V no es sino la amistad.

Parecería, en vista de esta afinidad "existencial", que el amigo número uno de Garcilaso fue Mario Galeota. Pero no. El amigo número uno fue sin duda Juan Boscán. ¿A pesar de que Boscán, unido en feliz matrimonio con doña Ana, nunca sufrió tormentas amorosas? Quizá más bien a causa de ello. Boscán debe de haber puesto en la relación amistosa algo que al neurótico Garcilaso le faltaba: ecuanimidad, serenidad, cordura. Garcilaso y Boscán tuvieron un trato personal y epistolar largo y asiduo, y los unía el lazo más firme y más hermoso: el amor a la Poesía. ${ }^{9}$ De ahí el lugar único que en la obra de Garcilaso tiene su "Epístoła a Boscán", inspirada por la amistad, como la Canción $\mathrm{V}$, pero cuyo tema mismo no es otro que la amistad:

Señor Boscán, quien tanto gusto tiene de daros cuenta de los pensamientos, hasta las cosas que no tienen nombre, no le podrá faltar con vos materia ni será menester buscar estilo presto, distinto, de ornamento puro, tal cual a culta epístola conviene...

Es, en efecto, una carta sencilla, hecha a vuelapluma, no en los cultos tercetos propios del género "epístola", sino en endecasílabos sueltos, libres del yugo de la rima. La carta está escrita el 12 de octubre (de 1534) en la ciudad "do nació el claro fuego de Petrarca / y donde están

${ }^{9}$ El encuentro de los dos poetas parece haber tenido lugar en el palacio del Duque de Alba. En la Égloga II dice Garcilaso que las bellas prendas de Fernando (el hijo mayor del Duque), "el trato, la crïanza y gentileza, / la dulzura y llaneza acomodada, / la virtud apartada y generosa" le han venido del ayo que tiene, y explica que este ayo "se llama / Boscán, de cuya llama clara y pura / sale el fuego que apura sus escritos, / que en siglos infinitos tendrán vida". (Profecía que ciertamente no llegó a realizarse.) 
del fuego las cenizas", o sea en Aviñón, patria de Laura, y donde poco antes se había "descubierto" su sepulcro. Doce días han pasado desde que Garcilaso salió de Barcelona, por tierra, camino a Nápoles. Doce días de viaje a caballo. El poeta está con los huesos molidos, pero ¡qué mejor descanso que escribirle al amigo! El mes de septiembre lo ha pasado en Barcelona, gozando el dulce trato de Boscán, y durante el viaje ha venido pensando en él, rumiando las conversaciones en que se habló de todo y de nada ("hasta las cosas que no tienen nombre"), y de estos pensamientos se nutre la carta. Entre los muchos bienes que proceden de la "amistad perfeta", dice, uno de los mayores "es aqueste descuido suelto y puro". Pensar en el bien de la amistad y pensar en Boscán son una sola cosa:

Iba pensando y discurriendo un día a cuántos bienes alargó la mano el que de la amistad mostró el camino, y luego vos, de la amistad ejemplo, os me ofrecéis en estos pensamientos...

Son muchos -prosigue- "los provechos, / las honras y los gustos que me vienen / destra vuestra amistad", pero lo más sabroso, lo más delicado, es la amistad misma, que no es sino uno de los rostros del amor. $Y$ es un amor sin complicaciones:

...el provecho, el ornamento,

el gusto y el placer que se me sigue del vínculo de amor, que nuestro genio enredó sobre nuestros corazones, son cosas que de mí no salen fuera, y en mí el provecho solo se convierte..., así que amando me deleito, y hallo que no es locura este deleite mío. 
ANTONIO ALATORRE

Tal es la carta. El lugar y la fecha van al final. Pero antes del final deja Garcilaso que irrumpa el buen humor. Seguramente le había dicho a su amigo en Barcelona: "Me prometo un viaje agradable; Provenza es una región deliciosa; caminos, posadas, vinos excelentes; los varletes (los valets, mozos de servicio) son muy atentos, las camareras muy bonitas, y todo es barato." Ahora, en Aviñón, tras doce días de vivir la realidad, comprende que debió haberse callado la boca:
¡Oh, cuán corrido estoy y arrepentido
de haberos alabado el tratamiento
del camino de Francia y las posadas!
Corrido de que ya por mentiroso
con razón me ternéis; arrepentido
de haber perdido el tiempo en alabaros
cosa tan digna ya de vituperio:
donde no hallaréis sino mentiras, vinos acedos, camareras feas, varletes codiciosos, malas postas, gran paga, poco argén, largo camino...

Y termina mandando saludar a un amigo común:

A mi señor Durall estrechamente abrazá de mi parte, si pudierdes...

("si pudierdes", porque, a lo que parece, el señor Durall era muy gordo). ${ }^{10} \mathrm{Es}$, en verdad, boni ta la naturalidad con que lo muy familiar se enlaza al discurso platónico sobre el amor y la amistad.

Garcilaso murió en octubre de 1536 y Boscán en septiembre de 1542 , no $\sin$ haber dejado lista la edición de sus poesías y las de su

${ }^{10} \mathrm{Creo}$ que nadie ha identificado a este personaje. Bien puede tratarse de Galceran Durall, oscuro poeta que escribió, en catalán, imitaciones de Ausias March. Véase Joan Ruiz i Calonja, Història de la literatura catalana, Barcelona, 1954, p. 381-2. 
amigo, que aparecieron juntas, y póstumas, al cuidado de la viuda. A sus noventa sonetos añadió Boscán otros dos - tal vez los últimos que escribió - en recuerdo de su amigo. El primero, "El hijo de Peleo celebrado...", compara a Garcilaso con Aquiles: "...tus trabajos hicieron larga historia, / y cúpote, tras esto, corta vida"; el segundo, "Garcilaso, que al bien siempre aspiraste...", es más llano, y también más personal, más efusivo.

El título de la primera edición, impresa en Barcelona a comienzos de 1543, dice así: Las Obras de Boscán y algunas de Garcilasso de la Vega repartidas en quatro libros. Las de Boscán ocupan tres "libros": el Primero contiene las coplas castellanas (escritas en los muy tradicionales octosílabos), el Segundo los versos a la italiana (canciones y sonetos) y el Tercero varios poemas largos en endecasílabos, sobre todo el desmesurado "Leandro", de casi 2,800 versos sueltos. El Cuarto libro contiene las obras de Garcilaso ("algunas", dice el título; pero son prácticamente todas las que de él nos quedan).

Al comienzo del Segundo libro insertó Boscán una carta a la Duquesa de Soma que sirve de prólogo y es un documento sin igual para la historia de la poesía en lengua española. Después de confesar el "miedo" de cansar a la ilustre señora con los muchísimos versos de sus tres libros, añade algo tranquilizador: "Aunque tras esto me acuerdo agora que el Cuarto libro ha de ser de las obras de Garcilaso, y éste no solamente espero yo que no cansará a nadie, mas aun dará grande alivio al cansancio de los otros." (Lo cual no suena de ninguna manera a falsa modestia.)

La novedad de los versos a la italiana ha sido muy bien recibida en España. No pocos españoles están haciéndolos ya. Y Boscán, sabiendo que a él le cupo en suerte ser el introductor, el pionero, cuenta con la mayor simplicidad la trascendentalísima conversación que tuvo un día, en Granada, con el señor Andrea Navagero, poeta y diplomático italiano. Le dijo Navagero que "por qué no probaba en lengua castellana sonetos y otras artes de trovas usadas por los buenos autores de Italia", y él, tras unos días de reflexión, comenzó “a tentar este género de 
ANTONIO ALATORRE

verso" y luego fue "poco a poco metiéndo[se] con calor en ello". Y en seguida agrega:

Mas esto no bastara a hacerme pasar muy adelante si Garcilaso con su juicio... no me confirmara en esta mi demanda. Y así, alabándome muchas veces este mi propósito, y acabándomelo de aprobar con su ejemplo (porque quiso él también llevar este camino), al cabo me hizo ocupar mis ratos ociosos en esto más fundadamente.

¡Bendita amistad, que tales frutos nos dejó! 